\title{
HUBUNGAN SELF-ESTEEM DAN KESEPIAN DENGAN KECENDERUNGAN GANGGUAN KEPRIBADIAN NARSISTIK PADA REMAJA PENGGUNA SOSIAL MEDIA INSTAGRAM
}

\author{
Jelang Hardika ${ }^{1}$, IGAA Noviekayati ${ }^{2}$, Sahat Saragih $^{3}$ \\ Universitas 17 Agustus 1945 Surabaya
}

\begin{abstract}
Abstrak
Tujuan penelitian ini adalah untuk mengetahui hubungan self-esteem dan kesepian dengan kecenderungan gangguan kepribadian narsistik pada remaja pengguna sosial media instagram. Penelitian ini merupakan penelitian kuantitatif korelasional. Teknik pengambilan sampel menggunakan purposive sampling. Sampel penelitian ini 109 remaja laki-laki dan perempuan berusia 12-22 tahun dan memiliki akun instagram aktif. Metode analisa data menggunakan regresi berganda dan uji hipotesa yang digunakan uji F dan Uji t Parsial. Hasil penelitian ini menunjukkan bahwa adanya hubungan positif yang signifikan antara selfesteem dan kesepian dengan kecenderungan narsistik yang dilihat dari uji $\mathrm{F}=4,813$ dan $\mathrm{p}=0,01(\mathrm{p}<0,05)$, maka $\mathrm{H} 1$ terima. Selanjutnya ada hubungan positif antara self-esteem dan kecenderungan narsistik, dimana uji $\mathrm{t}=2,681$ dan $\mathrm{p}=0,009(\mathrm{p}<0,05)$, maka $\mathrm{H} 2$ diterima. Hubungan yang ketiga adalah hubungan antara kesepian dengan kecenderungan narsistik, dimana uji $\mathrm{t}=3,048$ dan $\mathrm{p}=0,003(\mathrm{p}<0,05)$, maka H3 diterima.
\end{abstract}

Kata kunci: Self-esteem, Kesepian, Narsistik, Remaja, Sosial Media Instagram

\begin{abstract}
The purpose of this study was to determine the relationship of self-esteem and loneliness with the tendency of narcissistic personality disorder in adolescent social media instagram users. This research is a quantitative correlational. The sampling technique uses purposive sampling. The study sample included 109 male and female adolescents aged 12-22 years and had an active Instagram account. The results of this study indicate significant positive relationship between self-esteem and loneliness with narcissistic tendencies from the $F$ test $=$ 4.813 and $p=0.01$ ( $p<0.05)$, then $\mathrm{Hl}$ accepts. Then there is a positive relationship between self-esteem and narcissistic tendencies, where t test $=2.681$ and $p=0.009(p<0.05)$, then $\mathrm{H} 2$ is accepted. The third relationship is the relationship between loneliness and narcissistic tendencies, where t test $=3.048$ and $p=0.003(p<0.05)$, then H3 is accepted.
\end{abstract}

Keywords: Self-esteem, Loneliness, Narcissistic, Teenagers, Instagram Social Media

\footnotetext{
${ }^{1}$ hardikajelang@gmail.com

Magister Psikologi Profesi Universitas 17 Agustus 1945 Surabaya

Pumpungan, Sukolilo, Surabaya
}

Psikosains, Vol. 14, No.1, Februari 2019, hal. 1-13

P-ISSN 1907-5235

E-ISSN 2615-1529 


\section{Pendahuluan}

Semakin berkembangnya internet di seluruh dunia termasuk Indonesia berdampak pula pada berkembangnya situs-situs jejaring sosial (sosial media). Munculnya sosial media seperti facebook, twitter, path, dan instagram mengubah perilaku manusia dari berbagai aspek, seperti aspek sosial maupun kognitif. Berdasarkan aspek sosial yaitu berkurangnya komunikasi, interaksi, dan sosialisasi secara langsung, karena semua bisa tergantikan melalui dunia maya sosial media. Pada aspek kognitif manusia saat ini semakin ingin menunjukkan dan di akui siapa dirinya. Hal tersebut karena sosial media memberikan fitur-fitur seperti menulis status dan mengunggah foto maupun video. Seseorang bisa bercerita hal positif maupun negatif dari fitur status atau caption tersebut atau seseorang bisa mengunggah sebuah foto maupun video yang tujuannya adalah mendapatkan like atau tanggapan dari orang lain, seperti pujian atau apresisasi. Semakin bertambahnya pengguna sosial media dan semakin seringnya intensitas menggunkan sosial media akan mengubah perilaku seseorang, sekaligus memicu gangguan-gangguan psikologis jika terlalu berlebihan dalam menggunakan sosial media.

Beberapa kasus gangguan psikologi akibat terlalu sering mengakses sosial media seperti kasus remaja Di Newcasle, Inggris yang bernama Danny Bowman (19) yang mencoba bunuh diri dengan meminum obat-obatan hingga overdosis karena merasa foto selfie nya yang biasanya ia posting di facebook tidak ada yang sempurna. Beruntung ibunya mengetahui dan menyelamatkannya. Kasus tersebut dimuat dalam detik Health, Senin, 24 Mar 2014 10:46 WIB dengan judul "Kecanduan Selfie, Danny Hampir Bunuh Diri karena Fotonya Tak Sempurna". Kasus lain adalah kasus kecanduan selfie seorang pria di Essex, yang juga Inggris yang bernama Junaid Ahmed. Diberitakan setiap harinya ia harus mengambil foto dimanapun dan kapanpun, lalu mengunggahnya di instagram. Ahmed bisa mengambil foto selfie paling sedikit 200 kali dan akan menghapus fotonya di instagram jika tika mengantongi minimal 600 like. Ahmed tidak sampai bunuh diri jika hasil fotonya tidak sempurna, namun kecanduan selfie dan obsesi mendapatkan like sebanyakbanyaknya diinstagram tersebut membuat dirinya sampai melakukan operasi plastic agar penampilan lebih enak dipandang. Ahmed merasa kesulitan menghentikan kebiasaannya tersebut dan selalu terobsesi dengan penampilannya. Berita mengenai kecanduaan selfie dan likes instagram Junaid Ahmed tersebut termuat dalam internet situs Liputan6.com, pada 2 Maret 2018 dengan judul "Gila Selfie, Pria ini Unggah Foto 200 Kali Sehari di Instagram" Kasus-kasus tersebut adalah beberapa dari sekian banyak kasus yang terjadi karena pengguan sosial media yang berlebihan.

Hubungan Self-Esteem dan Kesepian dengan Kecenderungan Gangguan Kepribadian Narsistik pada Remaja Pengguna Sosial Media Instagram 
Instagram adalah sosial media yang sedang booming di Indonesia. Instagram adalah sosial media yang memberikan fitur pada penggunanya untuk mengunggah foto atau video kemudian pengguna menambahkan pesan (caption). Tujuan seseorang menguggah foto atau videonya di instagram adalah agar mendapat likes atau aperesisasi dari pengguna instagram yang lain. Pengguna instagram di Indonesia adalah terbanyak se Asia Pasifik sesuai berita yang di muat di Kompas, 27/07/2017, 11:48 WIB dengan judul "Indonesia, Pengguna Instagram Terbesar se-Asia Pasifik". Berdasarkan artikel tersebut didapatkan data dari 700 juta pengguna aktif bulanan alias Monthly Active User (MAU) yang diraup Instagram secara global, 45 juta di antaranya berasal dari Indonesia. Angka 45 juta MAU menunjukkan peningkatan yang signifikan jika dibandingkan dengan Januari 2016. Kala itu, MAU Instagram di Indonesia hanya 22 juta. Artinya pengguan instagram di Indonesia naik dua kali lipat di tahun 2017.

Kecenderungan narsistik di tahun 2018 bukanlah hal yang baru dan asing lagi. Misalnya contoh dalam sosial media instagram. Banyak dijumpai remaja yang mengunggah foto-foto pribadinya di sosial media tersebut. Ada sebagian yang kadang-kadang saja mengunggah foto, namun ada pula yang sering melakukan pengunggahan. Perilaku kebiasaan mengunggah foto pribadi di instagram tersebut tentu bukan tanpa alasan. Tentu remaja yang melakukan pengunggahan foto yang dilihat publik ingin mendapat perhatian dan tanggapan positif. Ingin dinilai cantik atau tampan atau menarik. Kemudian muncul istilah orang-orang yang suka berfoto selfie dan suka mengunggah foto di media sosial adalah orang yang narsis. Isitilah narsis terlihat sepele bagi banyak orang. Dalam anggapan masyarakat, kecenderungan narsis hanya orang yang bangga terhadap dirinya secara berlebihan dan tidak ada dampak negatif bagi diri sendiri atau bahkan merugikan orang lain. Pendapat masyarakat yang menganggap kecenderungan narsistik merupak hal yang wajar dan biasa tersebut adalah sebuah anggapan yang salah, karena kecenderungan narsistik dalam DSM-V (Diagnostic and Statistical Manual of Mental Disorders, Fifth Edition) secara klinis dikategorikan sebagai gangguan kepribadian.

Berdasarkan DSM-V (APA, 2012) individu dikatakan memiliki kecenderungan narsistik jika memiliki 5 dari 9 karakteristik berikut ini: melebihlebihkan kemampuan yang dimiliki, percaya bahwa dirinya spesial dan unik, dipenuhi fantasi tentang kesuksesan, kekuasaan, kecantikan/ketampanan, memiliki kebutuhan yang eksesif untuk dikagumi, merasa layak untuk diperlakukan istimewa, kurang berempati, mengeksploitasi hubungan, memiliki rasa iri terhadap orang lain atau menganggap orang lain iri kepadanya dan angkuh. 
Neale, et al (dalam Maria \& Sukamto, 2001) menambahkan bahwa seseorang dengan kecenderungan narsistik sangat sensitif terhadap kritik atau kegagalan walaupun tidak diperlihatkannya, karena sebenarnya memiliki harga diri yang rapuh. Fantasi yang tidak terbatas terhadap kesuksesan kecantikan, kekuasaan atau cinta ideal sering kali dijadikan topeng untuk menutupi harga dirinya yang rapuh. Hal ini berlaku juga pada model perempuan yang berkecenderungan narsistik. Berdasarkan pernyataan APA di DSM-V dan Neale, et al (dalam Maria \& Sukamto, 2001) tersebut membuktikan bahwa kecenderungan narsistik yang biasanya dianggap masyarakat sebagai bahan guyonan dan tidak membahayakan secara psikologis ternyata adalah sebuah gangguan psikologis yang bisa dikatakan cukup menyiksa penderitanya.

Pada tahun 2018 ini terutama dalam dunia sosial media orang dengan mudahnya menunjukkan siapa dirinya, seberapa sukses atau menarik dirinya. Wajar apabila masih dalam keinginan-keinginan yang sederhana, namun akan menjadi masalah apabila sudah ada indikasi obsesi untuk terus diperhatikan, disukai, dan dipuji orang lain. Karena secara perlahan akan mengarahkan seseorang menjadi pibadi yang memiliki kecenderungan narsistik. Neale, et al (dalam Maria \& Sukamto, 2001) mengatakan kecenderungan narsistik sangat sensitif terhadap kritik atau kegagalan, karena sebenarnya memiliki harga diri (self-esteem) yang rapuh.

Berdasarkan pernyataan Neale, et al (dalam Maria \& Sukamto, 2001) tersebut bahwa ternyata self-esteem dapat mempengaruhi seseorang memiliki kecenderung narsistik. Self-esteem yang rendah akan membuat seseorang berusaha menaikkan selfesteemnya dengan berbagai cara. Hal tersebut berlaku juga pada remaja. Ketika remaja tidak bisa mengaktualisasikan perilakunya secara langsung kepada orang lain untuk menaikkan self-esteemnya, maka remaja tersebut akan berusaha menunjukkan eksistensi dan aktualisasi dirinya di dunia maya dengan membuat status atau mengupload foto terbaiknya, yang tujuannya untuk mendapat perhatian, pujian atau apresiasi dari orang lain yang bisa meningkatkan self-esteemnya tersebut. Demikian juga dengan remaja yang memiliki self-esteem yang tinggi. Remaja yang memiliki self-esteem yang tinggi akan lebih mudah mengaktualisasikannya di depan orang lain. Remaja yang memiliki self-esteem yang tinggi, maka kebutuhan untuk diperhatikan dan diapresiasi orang lain juga semakin tinggi. Apabila kebutuhan ini belum cukup terpenuhi di kehidupan sehari-harinya, maka remaja sekarang akan mencoba memenuhinya di dunia maya. Intensitas mengakses sosial media dan menujukkan eksistensi secara berlebihan maka akan akan memicu remaja memiliki kecenderuangan narsistik.

Hubungan Self-Esteem dan Kesepian dengan Kecenderungan Gangguan Kepribadian Narsistik pada Remaja Pengguna Sosial Media Instagram Jelang Hardika, IGAA Noviekayati, Sahat Saragih 
Chaplin (2006) menyatakan bahwa self-esteem (harga diri) adalah penilaian diri yang dipengaruhi oleh sikap, iteraksi, penghargaan dan penerimaan orang lain terhadap individu. Self-esteem setiap orang memiliki kadar yang berbeda-beda, ada yang tinggi ada yang cukup tinggi dan ada pula yang rendah. Inti dari self-esteem adalah bagaimana seseorang memandang diri mereka sendiri apakah itu positif atau negatif. Apabila positif maka bisa dikatakan harga diri mereka tinggi dan apabila negatif maka dikatakan harga diri rendah. Sebagaimana dikemukakan oleh Morris Rosenberg (dalam Flynn, 2003) yang mendefinisikan self-esteem adalah suatu penilaian baik positif atau pun negatif terhadap suatu yang objek yaitu dirinya sendiri. Faktor yang mempengaruhi self-esteem menurut Ghufron (dalam Adilia, 2010) terdapat 2 faktor yang dapat mempengaruhi self-esteem, yaitu Faktor internal seperti jenis kelamin, intelegensi, dan kondisi fisik individu, sedangkan faktor eksternal berupa lingkungan sosial, sekolah, dan keluarga.

Berdasarkan pernyataan-pernyataan tersebut bisa dikatakan self-esteem adalah berbicara mengenai intrapersonal seseorang. Bicara bagaimana seseorang menilai dan memaknai diri mereka sendiri secara positif atau negatif. Seseorang yang memiliki self-esteem tinggi cenderung lebih percaya diri dibanding seseorng yang memiliki self-esteem rendah. Hal tersebut bisa juga dilihat ketika seseorang menggunakan sosial medianya, seperti instagram. Seseorang yang sering mengunggah foto ke instagram secara penilaian dari luar memiliki kepercayaan diri dan self-esteem yang tinggi, namun tentu tidak bisa dinilai begitu saja. Bisa saja seseorang yang kurang percaya diri dan memiliki self-esteem rendah malah sering mengunggah fotonya di instagram untuk menutup rasa percaya dirinya dan self-esteemnya yang rendah. Selfesteem seseorang yang rendah bisa dipengaruhi faktor eksternal maupun internal.

Faktor internal yang di maksud adalah seperti kurang percaya diri, kurang asertif, atau seseorang yang merasa kesepian. Seseorang yang tidak mampu menunjukkan dirinya secara langsung, kemudian dengan cara tidak langsung atau melalui dunia maya sosial media mereka menunjukkan siapa dirinya, seberapa menarik dirinya, dsb. Cara tersebut juga dilakukan untuk mendapatkan perhatian dan pujaan. Dalam teori psikologi sesuatu yang menyenangkan akan diulang, maka kegiatan tersebut akan terus dilakukan. Dampaknya tanpa disadari perlahan memiliki kecenderungan narsistik dan apabila penguatan tersebut terus dilakukan maka bisa membuat seseorang mengalami gangguan kepribadian narsistik.

Terdapat penelitian yang menemukan bahwa komunikasi secara online memiliki potensi untuk meningkatkan dukungan sosial dan harga diri sekaligus mengurangi kesepian dan depresi (Shaw \& Gant, 2002). Hal ini sependapat dengan Sundar (dalam Pittman \& Reich, 2016) bahwa instagram memberikan penurunan 
yang signifikan terhadap kesepian yang dialami oleh penggunanya sendiri. Dalam instagram individu dapat mengunggah foto atau video sesuai dengan yang diinginkan dengan harapan agar orang lain memberikan tanda suka (like) atau komentar yang ada di bawah foto atau video, ini menunjukkan bahwa keberadaan individu tersebut diterima dalam lingkungan sosial (Puspitasari, 2016), sehingga membuat indvidu mengunggah terus menerus foto atau video ke instagram.

Hasil riset yang dilakukan oleh Sadikides dkk.(2004) menyatakan bahwa faktor lain yang mempengaruhi kecenderungan narsisistik adalah kesepian. Penelitian yang dilakukan oleh Adi \&Yudiati (2009) juga menemukan bahwa kesepian menjadi salah satu faktor dari kecenderungan narsisistik. Kim, LaRose \& Peng (2009) mengatakan individu kesepian memiliki tingkat kecenderungan yang tinggi untuk melakukan interaksi sosial melalui media sosial.

Menurut Sampao (2005) kesepian adalah perasaan tersisihkan, terpencil dari orang lain karena merasa berbeda dengan orang lain, tersisih dari kelompoknya, merasa tidak diperhatikan oleh orang-orang disekitarnya, terisolasi dari lingkungan, serta tidak ada seseorang tempat berbagi rasa dan pengalaman. Kesepian yaitu kondisi emosi yang muncul ketika seseorang merasa asing, salah paham, atau ditolak oleh orang lain, tidak memiliki teman Rokach (dalam Yusuf, 2014).

Menurut Peplau \& Goldstone (dalam Yusuf, 2014). Kesepian berhubungan dengan kemampuan keterampilan sosial yang buruk, hubungan antar pribadi yang buruk, harga diri rendah, rasa malu dan penyesuaian sosial yang buruk. Individu yang kesepian umumnya berkepribadian introvert, pencemas, depresi dan neurotik. Individu yang kesepian menganggap dirinya banyak masalah karena mereka menarik diri dari hubungan sosial dan ini menyebabkan tingkat kecemasan tinggi dan berakibat terasing dari masyarakat. Berdasarkan pernyataan Peplau \& Goldstone (dalam Yusuf, 2014) terdapat pernyataan yang menyatakan bahwa kesepian berhubungan dengan beberapa hal, diantaranya yaitu harga diri yang rendah. Ternyata kesepian dan harga diri mempunyai hubungan.

Pernyataan Neale, et al (dalam Maria, et al, 2001) yang menyatakan salah seseorang narsistik sangat sensitif pada kritikan dan kegagalan karena memiliki harga diri yang rapuh juga menunjukkan bahwa self-esteem dan kecenderungan narsistik saling mempengaruhi. Hubungan antara kesepian dan kecenderungan narsistik juga saling mempengaruhi dengan di dukung hasil riset yang dilakukan oleh Sadikides dkk.(2004) menyatakan bahwa faktor yang mempengaruhi kecenderungan narsisistik adalah kesepian dan juga penelitian yang dilakukan oleh Adi \&Yudiati (2009) yang menemukan bahwa kesepian menjadi salah satu faktor dari kecenderungan narsisistik.

Hubungan Self-Esteem dan Kesepian dengan Kecenderungan Gangguan Kepribadian Narsistik pada Remaja Pengguna Sosial Media Instagram Jelang Hardika, IGAA Noviekayati, Sahat Saragih 
Berdasarkan hasil penelitian-penelitian diatas terdapat kesimpulan bahwa selfesteem, kesepian, dan kecenderungan narsistik saling berhubungan dan mempengaruhi. Ketika ada remaja yang cenderung berlebihan dan cenderung narsistik dalam sosial media khususnya instagram mengindikasikan ada permasalaah pada self-esteem dan kesepaian remaja tersebut, apalagi ada perbedaan perilaku remaja ketika berada pada lingkungan yang real dan perilaku di lingkungan dunia maya. Atas dasar itu peneliti bermaksud membuat penelitian tentang topik tersebut.

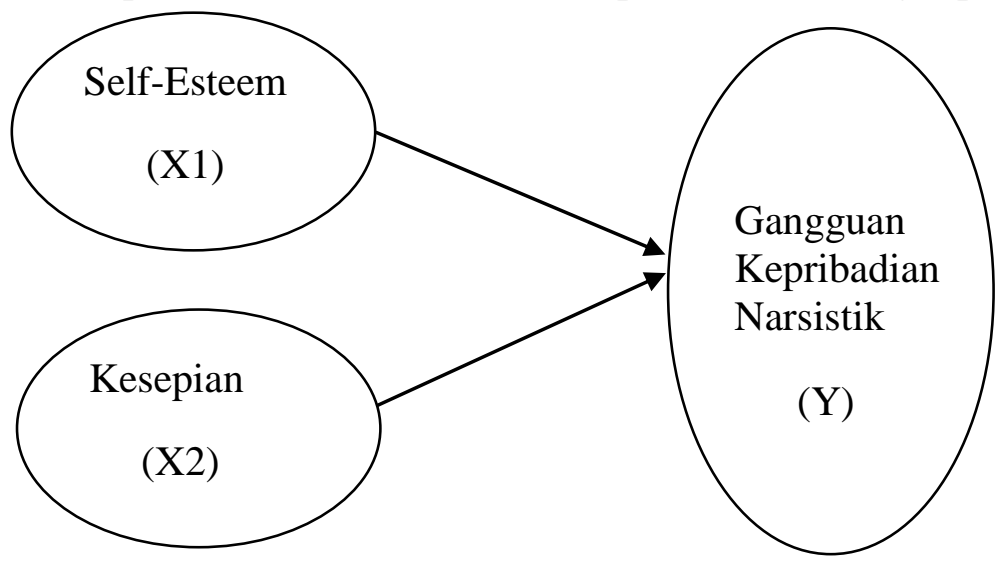

Gambar 1. Kerangka Konseptual

\section{Metode Penelitian}

Penelitian ini menggunakan pendekatan kuantitatif dengan pendekatan kuantitatif korelasional. Teknik pengambilan sampel menggunakan purposive sampling dengan karakteristik subjek yaitu remaja laki-laki maupun perempuan yang berusia 12-22 tahun yang memiliki akun instgram aktif. Instrumen data yang digunakan dalam penelitian ini adalah skala tentang Self-esteem, kesepian, dan narsitik buatan peneliti sendiri berdasarkan aspek-aspek teori yang ada.

Skala self-esteem dibuat berdasarkan aspek-aspek dari teori Coopersmith (Mruk, 2006) yang terdiri dari empat aspek, yaitu power (kekuatan), significance (keberartian), virtue (kebajikan), dan competence (kemampuan). Skala kesepian mengguanakan aspek-aspek dari Weiss (dalam Perlman, D., \& Peplau, L. A., 1998) membagi kesepian menjadi dua jenis yaitu, Emotional Loneliness dan Social Loneliness. Skala narsistik menggunakan aspek-aspek dari DSM V yang terdiri dari 9 ciri-ciri, yaitu

1. Merasa diri orang yang penting (seperti dalam hal pencapaian prestasi dan bakat, mengharapakan untuk diakui sebagai atasan tanpa prestasi yang sepadan)

2. Dipenuhi fantasi tentang kesuksesan, kekuatan, kecemerlangan, kecantikan/ketampanan, atau cinta yang ideal 
3. Percaya bahwa dirinya spesial dan unik

4. Memiliki kebutuhan yang eksesif untuk dikagumi

5. Merasa layak untuk diperlakukan istimewa

6. Mengeksploitasi hubungan (mengambil keuntungan dari orang lain untuk mencapai tujuannya sendiri)

7. Kurang berempati terhadap perasaan dan kebutuhan orang lain

8. Memiliki rasa iri terhadap orang lain atau menganggap orang lain iri kepadanya

9. Menunjukkan sikap dan perilaku yang angkuh.

Skala yang digunakan adalah skala likert dengan menggunakan skala sikap untuk variabel self-esteem dan kesepian dan skala perilaku untuk variabel narsistik. Skala sikap self-esteem dan kesepian menggunakan empat pilihan jawaban dengan pilihan sangat setuju (4), setuju (3), tidak setuju (2), dan sangat tidak setuju (1). Skala perilaku narsistik juga menggunakan empat pilihan jawaban, yaitu sangat sering (4), sering (3), jarang (2), jarang sekali (1). Teknik analisa yang diguanakan adalah regresi ganda dengan uji hipotesa menggunakan uji $\mathrm{F}$ dan uji t parsial dengan bantuan porgra SPSS 16.0 for windows.

\section{Hasil dan Pembahasan}

Berdasarkan hasil uji analisa regresi ganda Uji $\mathrm{F}$ diperoleh hasil uji $\mathrm{F}$ hitung = 4,813 dan $\mathrm{F}$ tabel $=3,08$ ( $\mathrm{F}$ hitung $>\mathrm{F}$ tabel) dan $\mathrm{p}=0,01(\mathrm{p}<0,05)$, maka hipotesa 1 diterima. Hal ini berarti ada hubungan yang signifikan antara self-esteem, kesepian, dan kecenderungan narsistik. Dapat ditarik kesimpulan bahwa self-esteem (X1) dan kesepian (X2) berpengaruh terhapat kecenderungan narsistik (Y).

Hasil dari uji t parsial variabel self-esteem dengan narsistik diperoleh nilai uji $\mathrm{t}=2,681$ dan $\mathrm{p}=0,009(\mathrm{p}<0,05)$, maka H2 diterima. Berdasarkan hal tersebut bisa dikatakan bahwa ada hubungan positif antara self-esteem dan kecenderungan narsistik. Artinya semakin tinggi self-esteem remaja, maka semakin tinggi pula kecenderungan narsistik remaja dan semakin rendah self-esteem remaja, maka kecnderungan narsistik remaja juga semakin rendah. Berdasarkan uji t parsial variabel kesepian dengan narsisk diperoleh nilai uji $\mathrm{t}=3,048$ dan $\mathrm{p}=0,003(\mathrm{p}<0,05)$, maka H3 diterima. Berdasarkan hal tersebut bisa dikatakan bahwa ada hubungan positif antara kesepian dan kecenderungan narsistik. Artinya semakin tinggi kesepian remaja, maka semakin tinggi pula kecenderungan narsistik remaja dan semakin rendah kesepian remaja, maka kecnderungan narsistik remaja juga semakin rendah.

Hubungan Self-Esteem dan Kesepian dengan Kecenderungan Gangguan Kepribadian Narsistik pada Remaja Pengguna Sosial Media Instagram 
Sosial media khususnya yang sedang booming saat ini, yaitu instagram mampu merubah psikologis manusia dari beragai aspek, seperti kognitif, sosial, maupun emosi. Sebelum tahun 2000 belum ada yang namanya sosial media, sehingga intensitas akifitas sosial sering dilakukan secara langsung, sehingga manusia cenderung lebih sosialis. Pada tahun 2000 keatas, sejak muncul dan boomingnya facebook sampai dengan yang sedang booming saat ini, yaitu instagram manusia cenderung banyak menghabiskan aktivitas sosialnya di dunia maya. Interkasi dan komunikasi yang bisanya di lakukan secara langsung kini terbagi menjadi komunikasi secara tidak langsung. Tidak ada menjadi masalah jika hal tersebut di lakukan dengan porsi yang wajar-wajar saja, namun akan menjadi masalah ketika aktivitas dunia maya telah menganggu bahkan merugikan aktivitas di dunia nyata.

Setiap remaja yang mengakses instagram akan cenderung memliki keinginan untuk diperhatikan dan dipuji yang tinggi. Hal tersebut akan membuat remaja memiliki kecenderungan narsistik. Bagi sebagian orang narsistik adalah hal yang lumrah saja, bahkan sebagian orang bangga dengan kenarsisannya. Padahal menurut DSM V narsistik merupakan suatu gangguan kepribadian. Ternyata meskipun terlihat sepele narisitik suatu hal yang perlu di sembuhkan. Gangguan kepribadian narsistik mungkin sedikit di kesampingkan daripada gangguan lain seperti stress, depresi, maupun trauma, namun gangguan kepribadian narsistik perlu di perhatikan mengingat era sosial media semakin berkembang pesat yang bisa berdampak gangguan kepribadian narsistik juga akan semakin meningkat juga.

Ketika seorang remaja memiliki self-esteem yang tinggi maka kebutuhan untuk dihargai dan diakui akan semakin tinggi juga. Adanya instagram menjadikan remaja yang memiliki self-esteem yang tinggi memiliki wadah untuk memenuhi kebutuhannya yang tinggi untuk di perhatikan dan di akui. Selain itu remaja yang memiliki self-esteem yang tinggi akan cenderung narsis di intagram karena remaja membutuhkan penerimaan dari orang lain baik itu secara langsung maupun diterima dalam pertemanan sosial media seperti instagram seperti pernyataan Coopersmith (dalam Ghufron, 2011) terdapat tiga aspek self-esteem yaitu, rasa diterima, rasa mampu, serta rasa dibutuhkan. Jadi remaja yang memiliki self-esteem yang tinggi akan memiliki kebutuhan diterima, dibutuhkan, dan kebutuhkan untuk menunjukkan kemampuannya, sehingga salah satu penyalurannya adalah melalui sosial media, seperti instagram. Ketika remaja narsis seperti dengan sering mengunggah foto, maka ketika remaja tersebut mendapatkan komentar positif, maka remaja tersebut akan merasa berharga.

Kebutuhan remaja untuk diperhatikan dan diapresisi sebenaranya merupakan hal yang wajar-wajar saja. Hal tersebut menjadi tidak wajar ketika dilakukan secara 
berlebihan dan sampai menganggu aktivitas maupun produktifitas belajar remaja. Bagaimanapun juga mencari perhatian, pengakuan, maupun apresiasi melalui sosial media merupakan hal yang semu, apalagi sebagaiman bentuk pelarian remaja yang tidak mendapatkannya di dunia nyata. Sosial media hanyalah media berinteraksi dan berkomunikasi secara tidak langsung tentu berbeda dengan berinteraksi secara langsung.

Remaja yang memiliki rasa kesepian yang tinggi akan merasa asing dan menganggap orang-orang disekitar tidak dapat mengerti dirinya, sperti menurut Sampao (2005). Kesepian adalah perasaan tersisihkan, terpencil dari orang lain karena merasa berbeda dengan orang lain, tersisih dari kelompoknya, merasa tidak diperhatikan oleh orang-orang disekitarnya, terisolasi dari lingkungan, serta tidak ada seseorang tempat berbagi rasa dan pengalaman.

Kesepian sendiri di bagi menjadi dua. Menurut Miller, dkk (2009) kesepian terbagi dalam dua tipe diantaranya:

1). Emotional Loneliness yaitu suatu bentuk kesepian yang diakibatkan oleh ketidakhadiran hubungan emosional yang intim.

2). Social Loneliness yaitu adanya perasaan dikucilkan dengan sengaja oleh lingkungan yang disebabkan tidak adanya keterlibatan diri dalam jaringan sosial tertentu.

Remaja kesepian tentuya memiliki permasalahan dengan orang lain, entah itu karena tidak dianggap, tidak diperhatikan, atau merasa tidak mau yang berteman denganya. Adanya permasalahan komunikasi dengan orang lain menjadikan orang yang memiliki kesepian yang tinggi ini mencari perhatian untuk mendapat tanggapan dari orang dengan sosial media.

Berdasarkan hal tersebut akan sulit bagi seseorang yang memiliki rasa kesepian yang tinggi untuk berkomunikasi maupun bersosialisasi dalam dunia nyata. Cara lain untuk menyelesaikan atau mengakhiri perasaan kesepian tersebut adalah dengan mengkases sosial media. Dalam sosial media seseorang bisa berkomunikasi dan berinteraksi tanpa secara langsung. Remaja-remaja yang tidak mendapatkan perhatian dari duni nyata akan merasa nyaman ketika mendapat perhatian dari dunia maya. Ketika sosial media lebih sering diakses otomatis intensitas untuk narsis juga akan semakin tinggi.

Kesepian yang tinggi bisa ditimbulkan dari berbagai sudut, bisa dari remaja yang tidak mampu bersosialisasi dan berinteraksi dengan baik di lingkungan keluarga maupun lingkungan sosialnya yang lain. Kesepian yang tinggi juga bisa disebabkan kerean lingkungan yang cenderung menolak seorang remaja, baik itu lingkungan keluarga maupun sosial. Kesepian merupakan suatu emosi negatif, untuk itu perlu 
diminimalisir sebanyak mungkin dengan cara lebih mudah membuka pikiran untuk bisa beradaptasi dan bersosialisasi di lingkungan manapun. Ketika seseorang merasa diterima dan berarti di lingkungan keluarga maupun sosial, maka kecenderungan kesepian yang tinggi akan cenderung menurun dan sekaligus menurinkan tingkat narsistik remaja di sosial media, terutama instagram.

\section{Kesimpulan}

Self-Esteem dan kesepian memiliki hubungan positif dengan kecenderungan narsistik. Semakin tinggi self-esteem, maka semakin tinggi pula kecenderungan narsistik remaja dan semakin rendah self-esteem, maka semakin rendah pula kecenderungan narsistik remaja. Hal tersebut sama juga dengan kesepian dan kecenderungan narsistik. Semakin tinggi kesepian, maka kecenderungan narsistik remaja juga akan semakin tinggi dan semakin rendah kesepian, maka kecenderungan narsistik remaja juga akan semakin rendah.

Remaja yaang memiliki kecenderungan narsistik yang tinggi perlu untuk melakukan kontrol penggunaan sosial media instagram. Kontrol disini bisa dengan melalukan pembatasan jam penggunaan instagram atau mengurangi intensitas mengakses instagram, misalnya jika setiap hari bisa mengakses instagram 12-15 kali bisa mengurangi 1-3 kali per minggu dan di lakukan secara bertahap. Pemberlakuan kontrol juga bisa denga megurangi intenstas mengunggah foto/video atau instastory instagram. Implikasi dari penelitian ini dapat dijadikan acuan untuk meminimalisir kecenderungan narsistik pada remaja denga cara memiliki self-esteem yang cukup, tidak kurang maupun berlebihan dan menjalin dan meningkatkan hubungan yang akrab dengan anggota keluarga maupun orang lain agar tidak memiliki perasaan kesepian yang tinggi.

\section{Daftar Pustaka}

Adi, P dan Yudiati, M.E.A. (2009) . Harga Diri Dan Kecenderungan Narsisme Pada Pengguna Friendster. Jurnal Psikologi Psikodimensia. Vol.3. No 1 (25-31).

Adilia, Dewi. Muharnia. (2010). Hubungan Self-Esteem dengan Optimisme Meraih Kesuksesan Karir pada Mahasiswa Fakultas Psikologi UIN Syarif Hidayatullah Jakarta. Skripsi (Tidak diterbitkan). Fakultas Psikologi. Universitas UIN Syarif Hidayatullah Jakarta. 
American Psychiatric Association. (2000). Diagnostic and Statistical Manual of Mental Disorders. Fourth Edition, Text Revision. Washington DC: APA.

Chaplin. (2006). Kamus Lengkap Psikologi (Terjemahan Kartini Kartono). Jakarta: PT Raja Grafindo Persada.

Flynn, H.K. (2003). Self-esteem theory and measurement: A critical review. Journal of feminist theory \& culture. Vol. 3.

Ghufron, M., N \& Risnawita, R., S. (2011). Teori-teori Psikologi. Yogyakarta: Ar Ruzz Media.

Kim, j., LaRose, R., \& Peng, W. (2009). Loneliness as The Cause and The Effect of Problematic Internet Use: The Relationship Between Internet Use And Psychological Well-Being. Journal Cyber Psychology and Behavior. 12 (14), $451-455$

Jeko I. R. (2018). “Gila Selfie, Pria ini Unggah Foto 200 Kali Sehari di Instagram”. Artikel majalah liputan 6 melalui link : https://www.liputan6.com/tekno/read/3335954/gila-selfie-pria-ini-unggahfoto-200-kali-sehari-di-instagram

Maria, H., Prihanto, S. \& Sukamto, E. 2001. Hubungan antara Ketidakpuasan Terhadap Sosok Tubuh (Body Satisfaction) dan Kecenderungan kepribadian narsistik Dengan Gangguan Makan (Kecenderungan Anorexia Nervosa dan Bulimia Nervosa). Anima, Vol 16, No. 3, 272-289.

Miller, Rowland S., Perlman, Daniel. (2009). Intimate Relationships. New York: Mc. Graw-Hill.

Mruk, C.J. (2006). Self esteem research, theory, and practice. New York: Springer Publishing Company

Pittman\& Reich. (2016). Social media and loneliness: Why an Instagram picture may be worth more than a thousand Twitter words. Computers in Human Behavior,62, 155-167. doi : http://dx.doi.org/10.1016/j.chb.2016.03.084 
Perlman, D., \& Peplau, L. A. (1998). Loneliness. In H. S. Friedman (Ed.) Encyclopedia of mental health, 2, (571-581). San Diego, CA: Academic Press.

Puspitasari(2016). Kebutuhan yang mendorong remaja untuk mem-posting foto atau video pribadi dalam instagram. Jurnal Psikologi Terapan. Vol 5, hal 75-84.

Sampao, Pornpen. (2005). Relationship of health status, family relations and loneliness to depression in older adult. Thesis. Psychiatric and Mental Health Nursing: Mahidol University.

Sedikides, Constantine, et al. (2004). Are Normal Narcissist Psychologically Healthy?: Self-Esteem Matters. Vol 87. Journal of Personality and Social Psychology. Southampton: American Psychogical Association.

http://dspace.ubvu.vu.nl/bitstream/handle/1871/17274/Sedikides_Journal\%20 of\%20Personality\%20and\%20Social\%20Psychology_87(3)_2004_u.pdf?sequ ence $=2$.

Shaw, L. H., \& Gant, L. M. (2002). In defense of the Internet: The relationship between internet communication and depression, loneliness, self-esteem, andperceived social support. Journal CyberPsychology \& Behavior. Vol 5, 157-171.

Yusuf, Rr.N.P., (2014). Hubungan Harga Diri Dan Kesepian Dengan Depresi Pada Remaja. Seminar Asean 2nd Psychology \& Humanity (C) Psychology Forum Umm, 19 - 20 Februari 2016 